\title{
The Power Usage Allocating System to Optimize Based on the Priority Load
}

\author{
Hartina N. Aidah ${ }^{1}$, Sekina Y. Trieksa ${ }^{11}$, Mohamad Ramdhani ${ }^{1}$, and Ahmad Sugiana ${ }^{1}$ \\ ${ }^{1}$ Electrical Engineering, Electrical Department, 40257 Telkom University, Indonesia
}

\begin{abstract}
Monitoring energy consumption in a household is an essential thing for optimization of electrical power usage. Unnecessary or excessive power usage can lead to power outages and damage the electronic devices, so the end-user needs a control device to overcome it. In this paper, we propose an easy-access device that can provide real-time information about energy consumption and optimization of power consumption. The method for current measuring is used ZMCT103c whose works on some transformer and for voltage measuring is used ZMPT101b whose works on step down transformer. This system is focused on loads management priority in study case boarding house with total active power 900 watts which are created to scaled loads allocation based on electronic devices susceptible to damage that caused by power outages with assumption 2 (two) rooms and 3 (three) loads each room. The system has priority mechanism for load usage that could not be shut down such as PC (personal computer) and refrigerator. The device works by distributing maximum $55 \%$ of active power from excess power room to needed power room so that can avoid power outages and increase the efficiency of power usage.
\end{abstract}

\section{Introduction}

Recently, The conservation of energy consumption is become very important [1] because the power source is limited, likewise the conservation of electrical energy consumption. Electrical energy usage increases on a building every year, so that increases the tariff also.

An excess of the power usage causes over capacity. Therefore it cuts off the current suddenly. In consequence, the optimization is required so that the power consumption more maximal. The optimization depends on the device identification which consumes more power and the development energy management technique $[2,3]$ which made on hardware. Every of these hardware has to communicating and to synergy for power usage accumulation, consumption cost of power usage, and allocating to efficiency electrical power [4].

The system implementation made on boarding-house with two rooms that have three loads in every room. In this system implementation, many researchers want to replenish the features of calculating and power consumption monitoring as the main feature on an

\footnotetext{
${ }^{1}$ Corresponding author: ysekina@gmail.com
} 
electrical system, so that used the current transformer as the current calculating which is the key for data acquisition [5]. Either wise, control device is needed for power consumption monitoring and allocating compatible with user's necessity. The process of electrical power allocate happened to compare the room's necessity with other room if the room needs more electrical power while the other room does not use it then the power on that other room would be allocated to the room whose needed. In other condition is when every room needed more electrical power so some loads would be shut off with the relay based on the load's priority scale [1].

The concept in this allocating system based on priority load research needs so that can maximal the available power without the user replenishing the power's capacity, with the result that more efficiency and resolving the problem that the electrical power source are limited. The system design is presented in section II, in section III is presented in the implementation design, the next section has presented the conclusion, and the last section is presented the future work.

\section{Design System}

Fig. 1 represents a general block diagram of the proposed system. This system made connected between electrical source voltage $220 \mathrm{~V}$ and MCB as a protector each room. The relay which midst MCB uses to do the power allocated. The main of a system is consist of the loads wiring, current and voltage sensor as measures and the relay located between the load and the Arduino as cuts the current to load.

Hardware planning consist of the component selection would be used, design planning and wiring. The point in this system is Arduino-Mega2560 usage. This component is a microcontroller that could be saved as the result of data processing to EEPROM memory [6]. Furthermore, the Arduino has a lot of port I/O so that could be implemented in a various room.

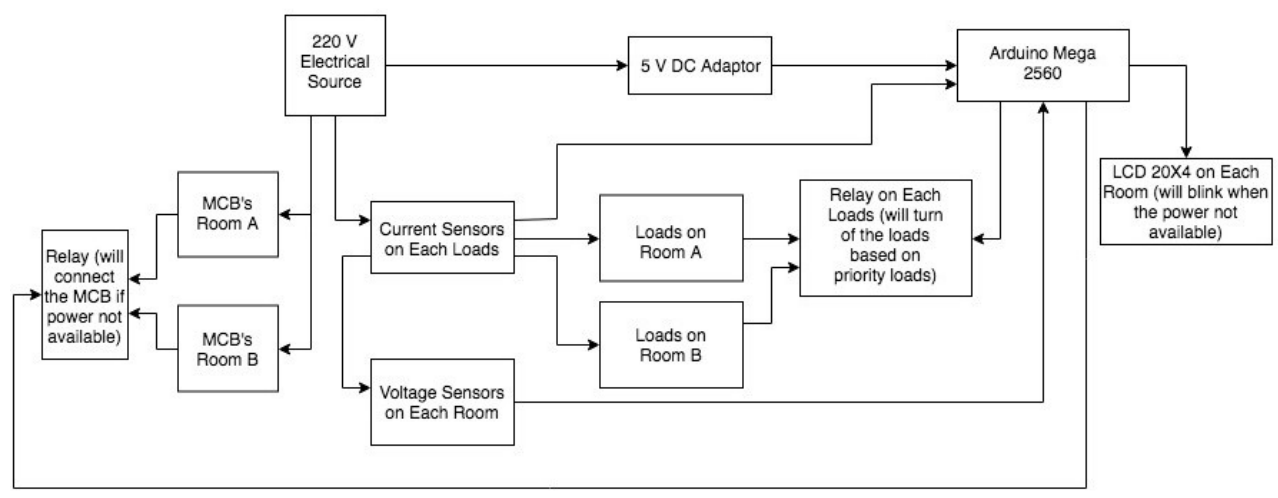

Fig. 1 General Block Diagram

\section{Implementation of the System}

In this implemented, there have been three processes to be used. The first is for current and voltage measurement [4], in part two is the processing of current and voltage data become the electrical power and long-time that the user used the loads with the assist by Real Time Clock DS3231. The next process is power management and allocating of power based on several conditions. This research is used in six loads with three loads in each room. 
To manage the loads, there are two systems [1]. The systems are the priority loads management and the allocating power.

\subsection{Allocating Power System}

The allocating power system happened when the room needs more power, and the other room only used less than the maximum total power in one room. This allocating coupled by connecting the relay inter each MCB in room 1 and the other room. For taking the resolve by the relay regarding the power that could be allocated or could not be allocated needs 1 minute and for taking back the power that would be observed by the current spring that happened on the room whose gave the power.

LCD installed on a panel for each room and displayed the total power consumption, tariff, and information that become the notification if the power is allocating approval or not. This LCD is useful for monitoring the power consumption.

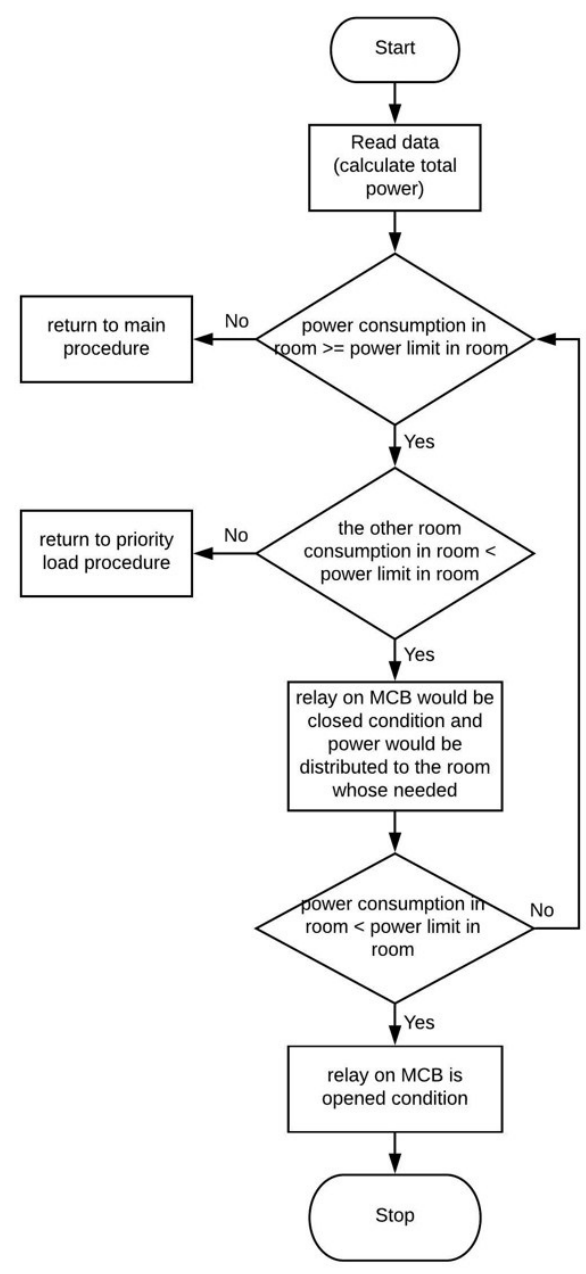

Fig. 2 Flowchart Allocating Power System [2] 


\subsection{Priority Loads Management}

The sequence of this priority needs to preserve the devices continuously turn on so that would not have happened the damage. The system is made by connecting the relay on every load's socket. The relay would be cut the current based on a specific condition and the sequence of loads priority $\mathrm{x}, \mathrm{y}$, and $\mathrm{z}$ those presented in Table 1

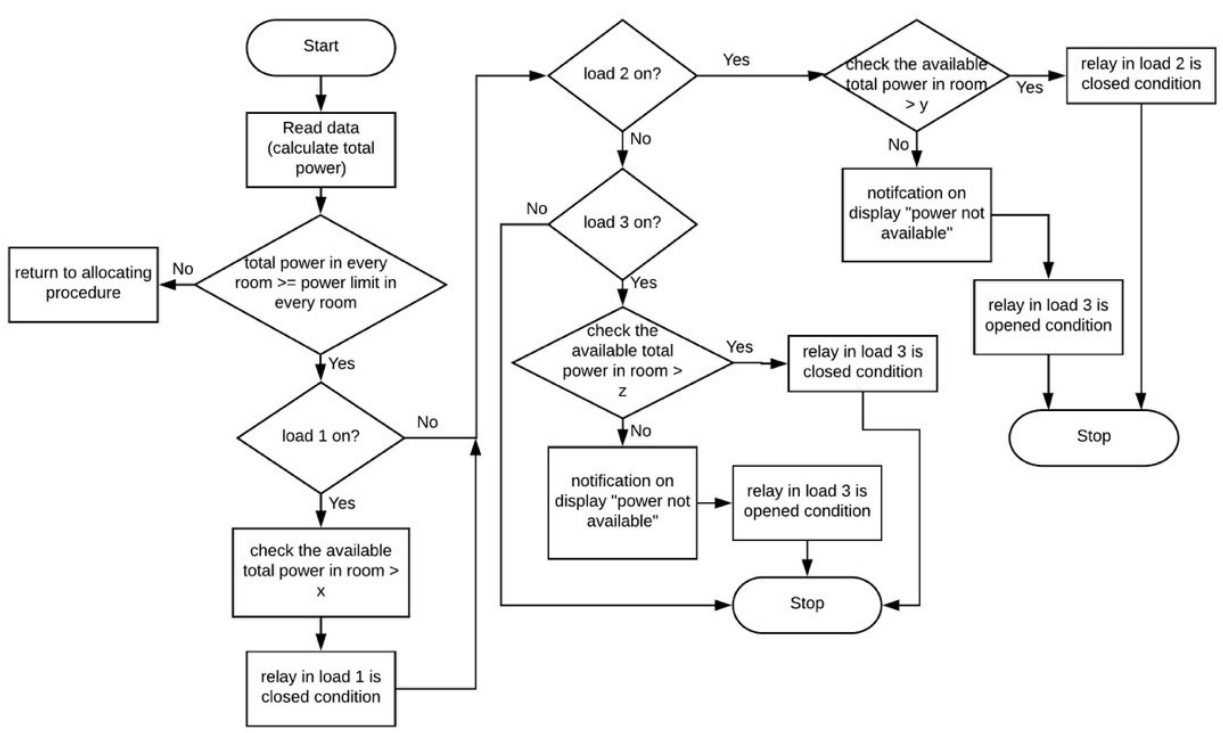

Fig. 3 Flowchart Priority Loads Management [2]

The allocating power and priority loads management, those two ways to manage power consumption that created the efficiency of power consumption. Table 1 showed the rules based on an amount the total power consumption for each room.

Table. 1 The rules for allocating power use system or priority load management

\begin{tabular}{|c|c|c|c|c|c|c|c|}
\hline \multirow{2}{*}{ Conditions } & \multicolumn{3}{|c|}{ Load Priority in Room 1} & \multicolumn{3}{|c|}{ Load Priority in Room 2} & \multirow{2}{*}{ Notes } \\
\hline & $\mathrm{x}$ & $\mathrm{y}$ & $\mathrm{z}$ & $\mathrm{x}$ & $\mathrm{y}$ & $\mathrm{z}$ & \\
\hline $\begin{array}{c}\text { Power } 1<450 \text { and } \\
\text { power } 2<450\end{array}$ & On & On & On & On & On & On & Normal Condition \\
\hline $\begin{array}{c}\text { power } 1>450 \text { and } \\
\text { power } 2<450\end{array}$ & On & On & On & On & Off & Off & $\begin{array}{l}\text { Allocating power } \\
\text { by room } 2\end{array}$ \\
\hline $\begin{array}{c}\text { Power } 1<450 \text { and } \\
\text { power } 2>450\end{array}$ & On & Off & Off & On & On & On & $\begin{array}{c}\text { Allocating power } \\
\text { by room } 1\end{array}$ \\
\hline $\begin{array}{c}\text { power } 1>450 \text { and } \\
\text { power } 2>450\end{array}$ & On & Off & Off & On & Off & Off & $\begin{array}{l}\text { Priority Load } \\
\text { Management }\end{array}$ \\
\hline
\end{tabular}




\subsection{Result}

Table. 2 Loads Priority and these Power Consumption [1]

\begin{tabular}{|l|c|c|c|}
\hline & \multicolumn{3}{|c|}{ Measurement Electricity Scale Variable } \\
\hline \multirow{2}{*}{ Loads } & Voltage RMS (V) & Current RMS (A) & $\begin{array}{c}\text { Calculation } \\
\text { Results }\end{array}$ \\
\hline (Watt)
\end{tabular}

Laptop and Personal Computer are devices which have tendency easier to be broken if the overpower happened so that these devices placed on top priority to maintained in on condition permanently when the current disconnected suddenly. These devices are created as a reference for determining power amount which maintained on each room. Based on measurement and real power calculation results in Table 2, then accepted the most significant total power is $P \approx 200 \mathrm{~W}$. Accordingly a percentage of the power could be allocated to other room :

$$
\begin{gathered}
P_{\text {share }}=P_{\text {total }}-P \\
\frac{P_{\text {share }}}{P_{\text {total }}} \times 100 \%=\frac{250}{450} \times 100 \% \cong 55 \%
\end{gathered}
$$

\section{Conclusion}

The power optimization can do with allocating the power from 1 room to another room in the amount of $55 \%$ by concern about the type of devices that tendency easier to be broken if the overpower happened. The first thing to do for optimization is set the devices that the user want to maintain in on condition even though the overpower happened. Furthermore, if the condition in each room uses the power $>450$ Watt, then automatically the relay will turn the device off based on the priority's scale.

\section{Future Work}

To develop this research in the future will be more useful if this system could be worked on a larger scale such as office complex, industry and others with many loads then this research.

\section{References}

1. R. Dubey, S. Nath, K. Harsha, D. R. S. Vinay, M. Bayya, Dr. BVSSN. P. Rao, "Smart Home Management with Online Power Measurement," IEEE: Humanitarian Technology Conference (R10-HTC), Dec (2016)

2. T. R. Melo, S. O. D. Luiz, "Experimental Platform for Power Measurements of Computer System," IEEE: Consumer Electronics - Berlin, Sept (2014) 
3. Y. S. Son, T. Pulkkenin, K. D. Moon, C. Kim, "Home Energy Management System based on Power Line Communication," IEEE: Transactions On Consumer Electronics, Vol: 56, No. 6, (2010)

4. E.Orsi, S. Nesmachnow, "Smart Home Energy Planning Using IoT and the Cloud," IEEE: URUCON, (2017)

5. Y. Thongkhao, W. Pora, "A Low-cost Wi-Fi Smart Plug with On-off and Energy Metering Functions," IEEE, (2016)

6. Arduino Mega 2560 Rev3, May 2018. [Online]. Available on: https://store.arduino.cc/usa/arduino-mega-2560-rev3 